\title{
Pseudotumor em artroplastia total do quadril metal-metal com cabeça de grande diâmetro*
}

\section{Pseudotumor in Large Diameter Head Metal-on-metal Total Hip Replacement}

\author{
Elmano de Araújo Loures ${ }^{10}$ Daniel Naya Loures ${ }^{2}$ Armando D'Lucca de Castro e Silva ${ }^{1}$ \\ Luiz Fernando Ribeiro Monte ${ }^{1}$ \\ ${ }^{1}$ Universidade Federal de Juiz de Fora (UFJF), Hospital Universitário, \\ Juiz de Fora, Brasil \\ 2 Universidade de São Paulo (USP), Hospital das Clinicas, Ribeirão Preto, Brasil \\ Address for correspondence Elmano de Araújo Loures, Universidade \\ Federal de Juiz de Fora (UFJF), Hospital Universitário, Juiz de Fora, MG, \\ Brasil (e-mail: loures.elmano@gmail.com).
}

Rev Bras Ortop 2019;54:87-89.

\section{Resumo \\ Palavras-chave \\ - reação tecidual adversa \\ - pseudotumor \\ - artroplastia total do quadril}

Os autores descrevem caso de artroplastia total do quadril (ATQ) com par tribológico metal-metal e cabeça de grande diâmetro que evoluiu com formação de pseudotumor inflamatório. O diagnóstico foi estabelecido por ressonância magnética com supressão de artefato metálico. O tratamento consistiu na ressecção do tecido anormal e revisão com par tribológico cerâmica-polietileno reticulado. Nenhum caso semelhante em língua portuguesa encontra-se descrito nas bases de dados PubMed, Scielo e Lilacs até a presente data.

The authors describe a case of a large diameter head metal-on-metal total hip replacement that evolved with an inflammatory pseudotumor formation. The diagnosis was established by magnetic resonance imaging (MRI) with suppression of the metal artifact. The treatment consisted on the resection of the abnormal tissue and on the revision to a ceramic on cross-linked polyethylene hip replacement. To this date, no similar case has been reported, in Portuguese language, in the PubMed, Scielo, and Lilacs databases.

\section{Introdução}

A busca por próteses articulares mais duráveis motivou a reintrodução do par tribológico metal-metal e posteriormente das cabeças de grande diâmetro. Em 2007, representaram 35\%

\footnotetext{
Trabalho desenvolvido no Hospital Universitário, Universidade Federal de Juiz de Fora (UFJF), e Hospital Albert Sabin, Juiz de Fora, MG, Brasil. Publicado originalmente por Elsevier Editora Ltda. (c) 2018 Sociedade Brasileira de Ortopedia e Traumatologia. (DI) Elmano de Araújo Loures's ORCID is https://orcid.org/0000-00033691-013X.
}

received

April 11, 2017

accepted

June 6, 2017

published online

November 28, 2017 das artroplastias totais do quadril (ATQ) nos Estados Unidos da América. ${ }^{1}$ Estima-se que mais de um milhão de implantes metal-metal foram vendidos no mundo e alguns milhares no Brasil. Às cabeças maiores se associou a modularidade dos implantes, favorecendo a tribocorrosão e reações teciduais adversas provocadas pelos debris metálicos produzidos nas múltiplas interfaces. Essas reações são mediadas por linfócitos e formam pseudotumores em alguns indivíduos. ${ }^{2,3}$ Trata-se de uma complicação grave, cujo reconhecimento precoce é essencial para uma resolução adequada. Os autores relatam caso de ATQ metal-metal com cabeça de grande diâmetro que evoluiu com formação de pseudotumor inflamatório.

Copyright $\odot 2019$ by Sociedade Brasileira License terms de Ortopedia e Traumatologia. Published by Thieme Revnter Publicações Ltda, Rio de Janeiro, Brazil
DOI https://doi.org/

10.1016/j.rbo.2017.06.021. ISSN 0102-3616. 


\section{Relato do Caso}

Indivíduo masculino, ex-atleta, 60 anos, coxartrose primária Tonnis III submetido à ATQ não cimentada com par tribológico metal-metal, cabeça de $50 \mathrm{~mm}$ e haste femoral com colo intercambiável. Evolução normal por 5 anos até aparecimento de dor inguinal, claudicação súbita e tumefação na região trocantérica. Ausência de flogismo, amplitude de movimentos preservada. Radiografias com implante normoposicionado, inclinação da cúpula 40。, sem linhas de demarcação e/ou osteólise (-Fig. 1). PCR normal, VHS 35/45, $\mathrm{Cr}=2,1 / \mathrm{Co}=4,1 \mu \mathrm{g} / \mathrm{L}$. Punção articular com líquido de coloração café-com-leite e culturas estéreis. Ressonância magnética com supressão de artefato metálico mostrou volumosa massa em partes moles que envolvia a região peritrocantérica e comunicava-se com a cápsula articular (-Fig. 2). Foi submetido a revisão da ATQ pela via lateral com ressecção da massa tumoral que envolvia parte do mecanismo abdutor e cápsula articular ( - Fig. 3). 0 componente acetabular fixo e sem sinais de desgaste foi removido e substituído por outro implante com inserto de polietileno reticulado e cabeça cerâmica de $32 \mathrm{~mm}$ (-Fig. 4). O colo intercambiável e suas conexões mostravam sinais da tribocorrosão e foi substituído (-Fig. 5). No seguimento aos 12 meses pós-revisão, o indivíduo encontrava-se assintomático e com parâmetros clínicos, radiológicos e laboratoriais normais.

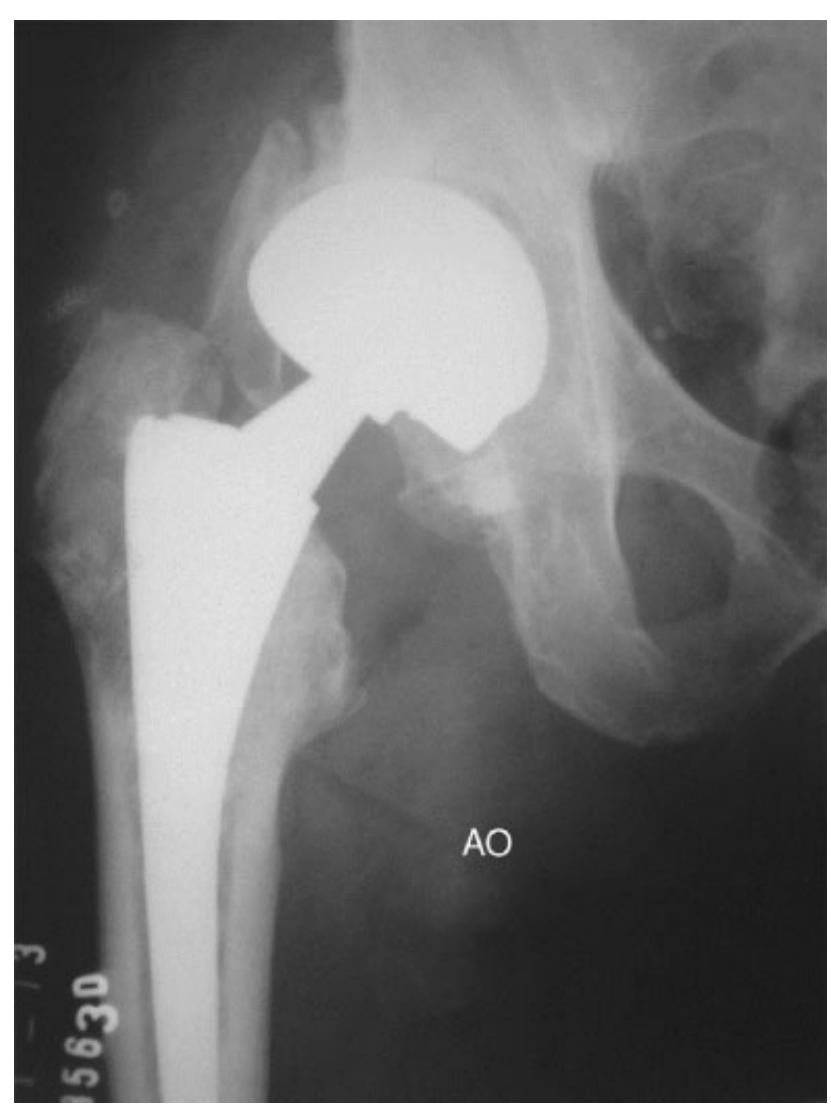

Fig. 1 Pré-op, cinco anos de evolução.



Fig. 2 RNM T2, notar a massa do pseudotumor.

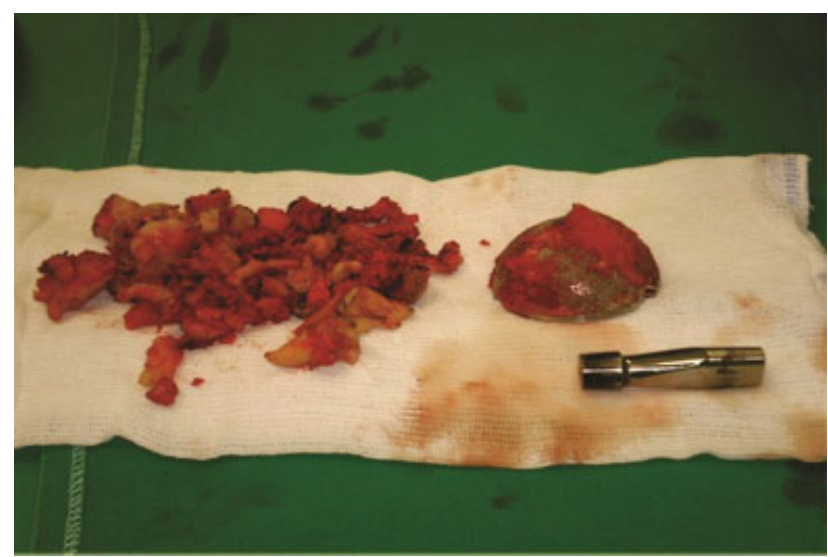

Fig. 3 Extensa massa de tecidos ressecados.

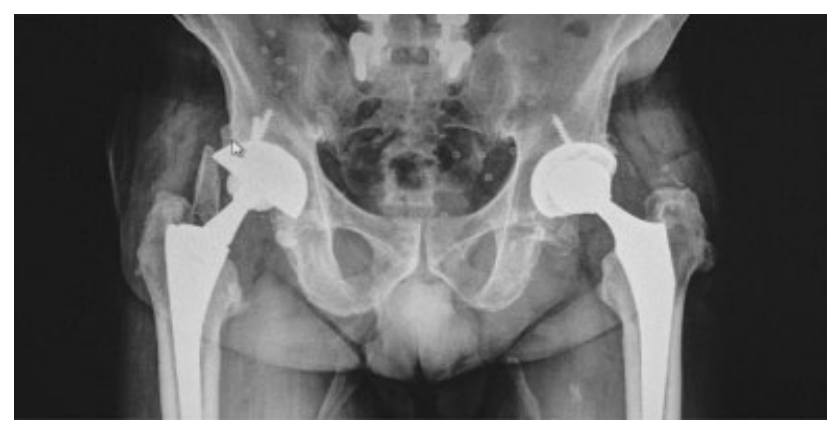

Fig. 4 Revisão à direita - PO, 12 meses. 


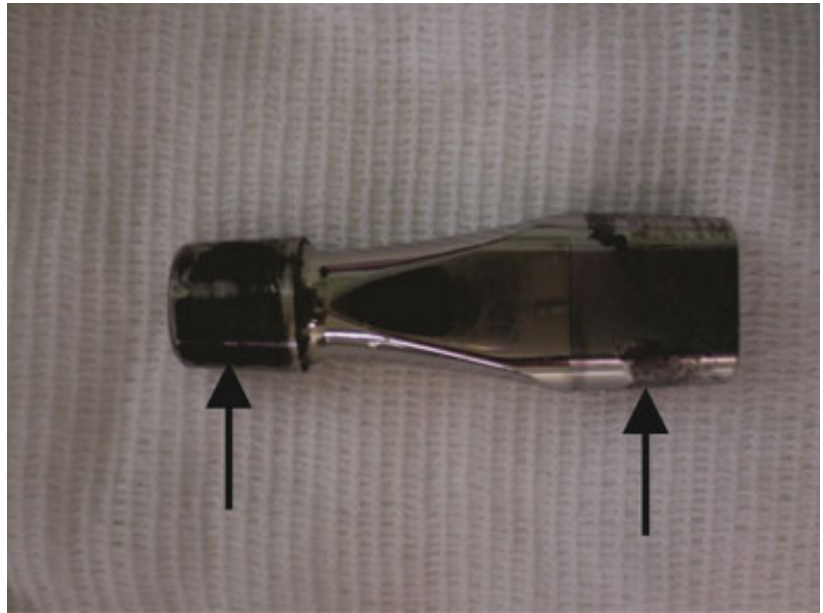

Fig. 5 Sinais típicos da tribocorrosão.

\section{Discussão}

O pseudotumor é descrito como uma massa semissólida ou cística, em tecidos moles periprotéticos com diâmetro acima de $2 \mathrm{~cm}$, que não possa ser atribuída a infecção, doença maligna, bursas ou tecido cicatricial. ${ }^{4}$

A ocorrência de pseudotumores e reações adversas aos debris metálicos em ATQ tem uma incidência elevada no par tribológico metal-metal se associado a cabeças de grande diâmetro e colo intercambiável. O fenômeno da tribocorrotecidual é reconhecido em todos os tipos de implantes e pares tribológicos. ${ }^{5-7}$

As reações teciduais adversas são supostamente resultantes da incapacidade do organismo de eliminar as micropartículas de metal oriundas das superfícies articulares e junções protéticas e/ou de alergia aos metais. A presença de cromo-cobalto é elemento essencial. Cúpulas com ângulo de abdução acima de 50。 em ATQs metal-metal estão mais propensas a reações adversas. $^{8}$

O torque friccional e o micromovimento nas conexões modulares produzem um quantitativo adicional de debris metálicos causado pelo dano na camada superficial do cone, o qual se soma às partículas produzidas na superfície articular. ${ }^{9} \mathrm{O}$ valor diagnóstico do aumento de níveis séricos de íons de cromo e cobalto é controverso. O quadro clínico e a ressonância magnética com supressão de artefato metálico são considerados a base do diagnóstico. O tratamento preconizado é a revisão da ATQ com a ressecção do tecido anômalo e a troca do implante, reduzindo-se ao máximo as interfaces metálicas. ${ }^{10}$
É mandatório o seguimento sistemático de indivíduos com ATQ metal-metal na busca do diagnóstico precoce de complicações, permitindo revisões antes que a destruição atinja grandes proporções e comprometa uma reconstrução. Qualquer implante com interfaces de conexão metálica pode desenvolver tribocorrosão, reações adversas teciduais e pseudotumores. Os pacientes com implantes metal-metal com cabeças maiores do que $32 \mathrm{~mm}$ compõem o grupo de maior risco.

Conflitos de Interesse

Os autores declaram não haver conflitos de interesse.

\section{Referências}

1 Bozic KJ, Kurtz S, Lau E, Ong K, Chiu V, Vail TP, et al. The epidemiology of bearing surface usage in total hip arthroplasty in the United States. J Bone Joint Surg Am 2009;91(7):1614-20

2 Bosker BH, Ettema HB, van Rossum M, Boomsma MF, Kollen BJ, Maas $\mathrm{M}$, et al. Pseudotumor formation and serum ions after large head metal-on-metal stemmed total hip replacement. Risk factors, time course and revisions in 706 hips. Arch Orthop Trauma Surg 2015;135(3):417-25

3 Fricka KB, Ho H, Peace WJ, Engh CA Jr. Metal-on-metal local tissue reaction is associated with corrosion of the head taper junction. J Arthroplasty 2012;27(8, Suppl)26-31.e1

4 Kop AM, Swarts E. Corrosion of a hip stem with a modular neck taper junction: a retrieval study of 16 cases. J Arthroplasty 2009; 24(7):1019-23

5 Cooper HJ, Della Valle CJ, Berger RA, Tetreault M, Paprosky WG, Sporer SM, et al. Corrosion at the head-neck taper as a cause for adverse local tissue reactions after total hip arthroplasty. J Bone Joint Surg Am 2012;94(18):1655-61

6 Fagotti L, Vicente JR, Miyahara HS, de Oliveira PV, Bernabé AC, Croci AT. Formation of a pseudotumor in total hip arthroplasty using a tribological metal-polyethylene pair. Rev Bras Ortop 2015; 50(6):747-51

7 Scully WF, Teeny SM. Pseudotumor associated with metal-onpolyethylene total hip arthroplasty. Orthopedics 2013;36(5): e666-70

8 Berry DJ, Callaghan JJ, Barrack RL, Bostrom MP, Browne JA, Greenwald AS, et al. Trunions, Tapers, and Corrosion in Total Hip Arthroplasty: What's All the Fuss About? What Every Surgeon Should Know. In: AAOS 2015 Annual Meeting -Instructional Course \#301 Lecture Handout 2015

9 Langton DJ, Sidaginamale R, Lord JK, Nargol AVF, Joyce TJ. Taper junction failure in large-diameter metal-on-metal bearings. Bone Joint Res 2012;1(4):56-63

10 Kwon YM, Lombardi AV, Jacobs JJ, Fehring TK, Lewis CG, Cabanela ME. Risk stratification algorithm for management of patients with metal-on-metal hip arthroplasty: consensus statement of the American Association of Hip and Knee Surgeons, the American Academy of Orthopaedic Surgeons, and the Hip Society. J Bone Joint Surg Am 2014;96(1):e4 